\title{
The Sonority Dispersion Principle in Albanian
}

\author{
Artan Xhaferaj \\ Department of Albanian Language and Literature, Faculty of \\ Humanities, "Ismail Qemali" University of Vlora, Albania
}

\section{Abstract}

An important pattern that is based on the sonority relationship is the Sonority Dispersion Principle (SDP) formulated by Clements (1990). This principle can serve as the basis for classifying syllable types in terms of relative complexity. The notion "dispersion in sonority" clearly defined within a demisyllable. According to this principle, the sonority slop from the onset to the syllable nucleus is maximized and from the nucleus to the coda is minimized. The purpose of this paper is to provide some data on the Albanian language by dividing the sounds within the demisyllable, by analyzing the combinations of sounds in the onset and in the coda. According to SDP, in Albanian the optimal syllable structure with 2 elements is $\mathrm{C}_{[\text {stop] }} \mathrm{V}$, while among the optimal structures with 3 elements, the types $\mathrm{C}_{\text {[stop] }} \mathrm{VC}_{\text {[glide] }}, \mathrm{C}_{\text {[stop] }} \mathrm{C}_{\text {[liquid] }} \mathrm{V}, \mathrm{C}_{\text {[stop] }} \mathrm{C}_{\text {[nasal] }} \mathrm{V}$ and $\mathrm{C}_{\text {[fricative] }} \mathrm{C}_{\text {[iquid] }} \mathrm{V}$ predominate. The analyzed data are important and serve to deeply recognize the characteristics of phonological system of Albanian and can also serve for its approach to typological level.

Keywords: Albanian language, syllable types, optimal syllable, demisyllable, Sonority Dispersion Principle

\section{Introduction}

The sonority notion is closely connected to the syllable concept. As it is known, the syllable is the basic unit on which the phonologic rules operate, in particular the rules of phonemes dispersion and combination. The sonority theory holds that syllable formation associates with the sonority degree of the sounds, which should be classified according to their acoustic features, whereas the number of syllables depends on the number of sonority peaks. As to the syllabic boundary, it lies where the greatest decline is, although this important issue is more clearly explained by certain sonority mechanisms, such as the Syllable Contact Law and the Sonority Dispersion Principle. In linguistic literature, according to the sonority degree, after vowels, which are the most sonic sounds, the position of glides, liquids, and nasals has been well-defined, since such sounds (including vowels too) have a clear formant structure. For obstruents, opinions differ (for further details see Parker, 2002). In general, from the acoustic viewpoint, different from the stops, the fricatives are clear 
sounds, voiced and of high intensity, in particular the sibilants. Scholars, however, who only divide obstruents in two classes, (fricatives > stops) usually rely on the binary feature [ \pm continuant]. Of a particular interest in distinguishing relative sonority between stops and fricatives is a work of Gnanadeskian (2004), based on the phonologic characteristics of her two-year-old daughter for a six-month period. In pronouncing the words sky and spill the onset consonant cluster was simplified: the initial fricative /s/ is deleted in the clusters /sk/ and /sp/, with the argument that it was more sonorous than the stops $/ \mathrm{k} /$ and $/ \mathrm{p} /$. We also analyzed this case in Albanian, by taking into consideration the phonologic characteristics of my own daughter (two and a half years old), which remained constant for a period of two months. The onset cluster, fricative + stop reduced while pronouncing the words stolí [toli] 'stool', ski [ki] 'ski', shkopi [kopi] 'the stick', shpoj [poj] 'to pierce', shtata [tata] 'seven', producing clearer onsets, as Gnanadeskian had remarked. Thus, for the Albanian language, we will prefer to group sounds in six main classes, as shown in Table 1.

Table 1. Phonetic version of relative sonority hierarchy in Albanian

A

\begin{tabular}{|c|c|c|c|}
\hline \multicolumn{3}{|c|}{ Classification of Albanian sounds } & Sonority index \\
\hline Vowels & (V) & $a, e, \ddot{e}, o, i, y, u$ & 6 \\
\hline Glides & $(G)$ & $j$ & 5 \\
\hline Liquids & (L) & $l, l l[t], r[\lrcorner], r r[r]$ & 4 \\
\hline Nasals & $(N)$ & $m, n, n j[n]$ & 3 \\
\hline Fricatives & (F) & $f, v, \operatorname{th}[\theta], d h[\delta], s, z, \operatorname{sh}\left[\int\right], z h[3], h$ & 2 \\
\hline $\begin{array}{l}\text { Stops } \\
(+ \\
\text { affricates) }\end{array}$ & $(S)$ & $\begin{array}{l}p, b, t, d, k, g, q[c], g j[t], \\
c[t s], x[d z], c[t]], x h[d z]\end{array}$ & 1 \\
\hline
\end{tabular}

simple syllable of the CVC structure is the one in which sonority disperses maximally at the onsets and maximally falls at the codas, while the preferred sonority profile for the structure $\mathrm{CV}$ requires that the consonant have a lower sonority. Albanian has fewer limitations than other languages about the number of segments that can appear at the onsets and the codas.

\section{Methodology}

Through an analytic approach, we have identified the combinations of phonemes in initial and final demisyllables, using material from the Dictionary of Present-day Albanian (1980). Based on the analyzed and interpreted data, we have determined the optimal and complex structures of demisyllables of two and three constituents in the Albanian language. Furthermore, in order to have an additional argument in distinguishing relative sonority between obstruents in Albanian, we observed the phonologic characteristics of my two-and-a-half-year-old daughter, Ares, which were the same as those of two more children of the same age, Amaris and Bora. The children lived in a setting where only standard Albanian is used, and they produced simple syllables, reducing the complex onsets of two constituents into one single consonant, 
in agreement with the sonority requirements. More detailed data on the reduction of onset clusters have been given in Appendix.

\section{Sonority Dispersion Principle and demisyllables in Albanian}

An important model relying on the sonority of sounds relations is the Sonority Dispersion Principle offered by Clements (1990). This principle may serve as a basis for the classification of syllable types according to relative complexity. Following this principle, the sonority slope maximizes from the onset to the nucleus and minimizes from the nucleus towards the coda. In order to make the principle more comprehensible, Clements (1990) explains the demisyllable notion: The syllable is divided in two overlapping parts called demisyllables; the syllable nucleus belongs to both parts simultaneously. According to this author, the demisyllable is a maximal sequence of tautosyllabic segments of the form $C_{m} \ldots C_{n} V$ or $V C_{m} \ldots C_{n}$, where $n \geq m \geq 0$. The fundamental idea in using the demisyllable is that the sonority profile of the first part of the syllable is independent of the sonority profile of the second part. In this way the attribute "dispersion in sonority" is best defined over the demisyllable.

The dispersion principle requires that the preferred initial demisyllable maximizes the sonority dispersion, whereas the preferred final demisyllable minimizes it. Let us illustrate this with an example in the Albanian language. In the disyllabic word [qortim] 'rebuke', each syllable is divided in two demisyllables: an initial demisyllable and a final demisyllable; the demisyllable on the left is [qo] and the demisyllable on the right is [or]. In the first demisyllable sonority increases from the stop /q/ to the vowel $/ \mathrm{o} /$, having thus a maximal dispersion of sonority (that is, the distance between the extremes of the scale), while in the second demisyllable there is a less intensive dispersion, since sonority falls from the vowel /o/ to the liquid / $\mathrm{r} /$. The second syllable follows the same pattern, as can be seen in Figure 1.

Figure 1. The syllable structure and the demisyllables of the word qortim "rebuke"



According to Clements (1992), the notion "dispersion in sonority" can be calculated 
in terms of the sum of the reciprocal of the squared values of the sonority distances, $d$, between the members of each pair of segments in the demisyllable. Dispersion is inversely connected with the value of $D$ in the following formula:

$$
D=\sum_{i=1}^{m} \frac{1}{\mathrm{~d}_{i}^{2}}
$$

where $d$ indicates the distance in the sonority scale of each pair of segments that forms in the demisyllable (including the non-adjacent segments), which is acquired by the formula $n(n-1) / 2$, where $n$ stands for the number of segments.

By means of the above formula, based on the values of $\mathrm{D}$ we can define the relative complexity rankings for demisyllable types in Albanian language, assuming the sonority scale, as shown in Table 1.

Table 2. CV and VC demisyllables in Albanian

\begin{tabular}{llllll}
$\begin{array}{l}\text { Initial } \\
\text { demisyllable }\end{array}$ & $\begin{array}{l}\text { Complexity } \\
\text { ranking }\end{array}$ & $\begin{array}{l}\text { Final } \\
\text { demisyllable }\end{array}$ & $\begin{array}{l}\text { Complexity } \\
\text { ranking }\end{array}$ & $\begin{array}{l}\text { Value } \\
\text { of D }\end{array}$ \\
\hline$S V$ & 1 & $V S$ & 5 & $=$ & 0.04 \\
$F V$ & 2 & $V F$ & 4 & $=$ & 0.06 \\
$N V$ & 3 & $V N$ & 3 & $=$ & 0.11 \\
$L V$ & 4 & $V L$ & 2 & $=$ & 0.25 \\
$G V$ & 5 & $V G$ & 1 & $=$ & 1.00 \\
\hline
\end{tabular}

As

indicated by the data in Table 2, the initial demisyllable of two elements stop + vowel has a better sonority profile followed by other demisyllables: fricative + vowel, nasal + vowel etc. Thus, the lower the values of $\mathrm{D}$, the more optimal is sonority profile of the initial demisyllables. In general, in Albanian predominate the open syllables, and the syllable structure $\mathrm{CV}$ is the most common pattern. On the other hand, sonority profile is better for the final demisyllables, which have higher values of D. So, the final demisyllable type vowel + glide is the simplest, whereas the combination vowel + stop is the most complex. When the initial demisyllable consists of only a vowel, it has a more complicated sonority profile than any structure of two elements (Clements 1992). In this case, the start of the vowel articulation gets stronger, and this strengthening sometimes leads to the creation of prothesis (Sawicka, 2018). Such an occurrence appears in the conversational speech of Albanian, although certain instances have been recorded in written language too, as in avash 'slowly' $>$ havash, but also kavash, arrin 'arrive' > harrin, ik 'go away' > hik, erdha 'came' > herdha, ec 'go' $>$ hec, opingw 'Albanian leather shoes like moccasins' > hopinge, ap 'give' > jap, osh 'seduce' > josh etc.

Among the simpler initial demisyllables of three elements, according to the SDP, Albanian contains the structures SLV, SNV and FLV, because they have the lowest values of $\mathrm{D}$, whereas the more complex initial demisyllables have the combinations NGV, NLV, and LGV (See Tab. 3). 
Table 3. CCV and VCC demisyllables in Albanian

\begin{tabular}{llllll}
\hline $\begin{array}{l}\text { Initial } \\
\text { demisyllable }\end{array}$ & $\begin{array}{l}\text { Complexity } \\
\text { ranking }\end{array}$ & $\begin{array}{l}\text { Final } \\
\text { demisyllable }\end{array}$ & $\begin{array}{l}\text { Complexity } \\
\text { ranking }\end{array}$ & $\begin{array}{l}\text { Value } \\
\text { of } D\end{array}$ \\
\hline SLV, SNV & 1 & $V L S, V N S$ & 6 & $=$ & 0.40 \\
$F L V$ & 2 & $V L F$ & 5 & $=$ & 0.56 \\
$S G V, S F V$ & 3 & $V G S, V F S$ & 4 & $=$ & 1.10 \\
$F G V, F N V$ & 4 & $V G F, V N F$ & 3 & $=1.17$ \\
$N G V, N L V$ & 5 & $V G N, V L N$ & 2 & $=1.36$ \\
$L G V$ & 6 & $V G L$ & 1 & $=2.25$ \\
\hline
\end{tabular}

Furthermore, the initial demisyllables of the types SLV, SNV, and FLV are more harmonious, as the liquids and the nasals are positioned almost in the middle of the scale extremes, which not happens with the complex demisyllables (See Fig. 2). However, it should be emphasized that, although the demisyllables of the types SLV and SNV have the same value of D, the two-element combinations of the type stop + liquid at onsets occur more frequently in Albanian than the combinations stop + nasal and fricative + liquid.

Figure 2. a. Harmonic demisyllable types: $\mathrm{C}_{\text {[stop] }} \mathrm{C}_{\text {[liquid or nasal] }} \mathrm{V}$ and $\mathrm{C}_{\text {[fricative] }} \mathrm{C}_{\text {[iquid] }} \mathrm{V}$

b. Complex demisyllable types: $\mathrm{C}_{\text {[nasal] }} \mathrm{C}_{\text {[liquid or glide] }} \mathrm{V}$ and $\mathrm{C}_{\text {[liquid] }} \mathrm{C}_{\text {[glide] }} \mathrm{V}$



complex demisyllables, they have a less frequent usage. The combination LGV is found in initial positions, in words starting with the two-element group /rrj/ + V (e.g. rrjedh 'to flow'), while the combinations $/ \mathrm{lj} /+\mathrm{V}, / \mathrm{llj} /+\mathrm{V}$ and $/ \mathrm{rj} /+\mathrm{V}$ appear in other than initial positions, as part of the onset of the second or third syllable in various words, as for instance, da-lje 'exit', ma-rrje 'reception', va-llja 'the dance' etc. Also, the combination NGV appears in words starting with /mj/ + V (e.g. mjaltë 'honey'), whereas the combination NLV occurs in words starting with $/ \mathrm{ml} /+\mathrm{V}$ (e.g. mlysh the fish pike'), /mll/ + V (e.g. mllef 'rancor'), /mr/ + V (e.g. mrekulli 'miracle') and /mrr/ $+\mathrm{V}$ (e.g. mrrudh 'to wrinkle'). Owing to the difficulty in articulating the initiating group $/ \mathrm{mr}-/$ and $/ \mathrm{ml}-/$, in standard Albanian, the usage of the words in which the vowel /ë/ or a plosive consonant is inserted between a nasal or a liquid becomes more and more frequent. For instance, in the standard Albanian vocabulary there 
exist 14 words with the initiating group $/ \mathrm{mr}-/, 50$ words starting with the combination /mër-/ and 55 words with the group /mbr-/ (for further details see Graph 1).

Graph 1. Usage frequencies of combinations /ml-/, /məl-/, /mbr-/, /mr-/, /mər-/, /mbr-/, /nr-/, /ndr-/ and /ngr-/ in word-initial position in Albanian.



As can be seen from the graph, in Albanian, the group /nr-/ does not exist at initial position, while the initial position groups /ndr-/ and /ngr-/ have a more frequent use. In fact, in Albanian, the groups sonant nasal + plosive /mb/, /nd/, /ng/, /mp/ are homorganic; their articulation is compound, and their occurrence at the initial position of words is one of the features of the Albanian language that distinguishes it from the other Balkan languages.

\section{Discussion}

Based on the analyzed data and linguistic literature, unlike Dodi (2004) and Memushaj (2015), we prefer to classify Albanian speech sounds according to sonority in 6 classes, as can be seen in Table 1 .

As part of my research, other interesting data are that initial be-consonantal clusters of type stop + liquid, stop + nasal and fricative + liquid, that are part of harmonic demisyllables, have more frequent usage in Albanian, while the initial be-consonantal clusters of type liquid + glide, nasal + glide and nasal + liquid, which are part of complex demisyllables, have a less frequent usage.

Likewise, the Sonority Dispersion Principle, as a mechanism of sonority, provides better solutions to syllable boundary determination: the syllabification rules became clearer, simpler and more generalizing in practical application.

\section{Conslusions}

As Clements notes, the ideal sonority contour is defined on the demisyllable, rather than on the onset or coda cluster alone. The Albanian language, like English, Spanish and other well-studied languages show a general preference for final demisyllables with low sonority dispersion, especially in non-final syllables. In the CV structures, 
the higher possible value of sonority dispersion (that is, the distance between the scale extremes) is 5, and in this way, according to the Sonority Dispersion Principle, the optimal initial demisyllable is SV, followed by FV, NV etc., whereas LV and GV are complex demysilables. The final demisyllable of type $\mathrm{VG}$ and $\mathrm{VL}$ are simpler than $\mathrm{VF}$ or VS. Concerning the initial demisyllables of type CCV, Albanian show a general preference for SLV over SGV, SLV over SNV, FLV over FGV and FLV over FNV. SLV, SNV and FLV are harmonic initial demisyllables, whereas NGV, NLV and LGV are more complex. According to SDP, also in Albanian VCV structure is preferably syllabified V$\mathrm{CV}$, not $\mathrm{VC}-\mathrm{V}$, since $\mathrm{V}$ is a simpler final demisyllable than VC; $\mathrm{CV}$ is a simpler initial demisillable than $\mathrm{V}$, whereas $\mathrm{VC}_{1} \mathrm{C}_{2} \mathrm{~V}$ structure is preferably syllabified $\mathrm{VC}_{1}-\mathrm{C}_{2} \mathrm{~V}$, when $\mathrm{C}_{1}$ is more sonorous than $\mathrm{C}_{2}$ and $\mathrm{V}-\mathrm{C}_{1} \mathrm{C}_{2} \mathrm{~V}$ when $\mathrm{C}_{2}$ is more sonorous than $\mathrm{C}_{1}$.

\section{References}

[1] Beartsch, K. (2010). Coda Formation vs. Onset Maximization: Issues in the Syllabification of VCV Sequences. Language Research, Vol. 46, No 1, 39-57.

[2] Clements, G. N. (1990). The role of the sonority cycle in core syllabification. In J. Kingston and M. E. Beckman, eds. Papers in laboratory phonology I. Cambridge: Cambridge University Press, 283-333.

[3] Clements, G. N. (1992). The sonority cycle and syllable organization. In Wolfgang U. Dressler, Hans C. Luschutzky, Oskar E. Pfeiffer and John R. Rennison, eds. Phonologica 1998. Cambridge: Cambridge University Press, 6376.

[4] Dodi, A. (2004). Fonetika dhe fonologjia e gjuhës shqipe, (The Phonetics and Phonology of the Albanian language). Tirana: The Albanian Academy of Sciences.

[5] Eddington, D., Treiman, R., \& Elzinga, D. (2013). Syllabification of American English: Evidence from a Large-scale Experiment. Part II, Journal of Quantitative Linguistics, Vol. 20, No. 2, 75-93.

[6] Gnanadeskian, A. (2004), Markedness and faithfulness constraints in child phonology. In Constraints in Phonological Acquisition, UK: Cambridge University Press, 73-108.

[7] Goldsmith, J. (2011). The Syllable. In Handbook of Phonological Theory, Second Edition (eds J. Goldsmith, J. Riggle and A. C. L. Yu), Wiley-Blackwell, Oxford, UK.

[8] Gussenhoven, C., \& Jacobs, H. (2011). Understanding phonology. London: Hodder Education.

[9] Jubani, A. (2012). Fonetikë akustike - Analizë e sistemit fonologjik (Acoustic Phonetics - Analysis of the phonological system), Tirana.

[10] Karagjozi, M. (2007). Rreth kombinimit të bashkëtingëlloreve në kufi të morfemave (About the combination of consonants at the morpheme boundaries), SF (Philological Studies), 1-2, Tirana.

[11] Katamba, F. (1996). An introduction to phonology (Eigth impression). London: Longman. 
[12] Ladefoged, P., \& Johnson, K. (2011). A Course in Phonetics. (6th ed.), Boston: Wadsworth, Cengage Learning.

[13] Memushaj, R. (2015). Fonetika e shqipes standarde (The phonetics of Standard Albanian), Tirana: Infobotues.

[14] Parker, S. G. (2002). Quantifying the sonority hierarchy. Doctoral dissertation.University of Massachusetts, Amherst.

[15] Rugova, B. (2019). Lexicon of Phonetics and Phonology Terms, Prishtina: Kosova Academy of Sciences and Arts.

[16] Sawicka, I. \& Dargiel K. (2018). The structure of Albanian syllable, Prishtina: Kosova Academy of Sciences and Arts.

[17] Topalli, K. (2007). Fonetika historike e gjuhës shqipe (Historical Phonetics of Albanian), Tirana: Dituria.

[18] Xhaferaj, A. (2018). Syllabification of bi-consonantal clusters between vowels in Albanian. In International Journal of English Linguistics; Vol. 8, No. 5, 230237, Canadian Center of Science and Education.

[19] Xhaferaj, A. (2018). The Syllable and some controversial issues about the syllable division in Albanian language. In ICTEA Journal; Vol. 7, Cosenca, Italy,114-120.

\section{Apendix}

Reduction of initial onset clusters to a single consonant in Albanian

\begin{tabular}{|c|c|c|c|c|c|}
\hline & Initial clusters & & Words & & Pronunciation \\
\hline \multirow[t]{8}{*}{ a) } & $S+L \rightarrow S$ & $b l>b$ & blu & 'blue' & [bu] \\
\hline & & $d r>d$ & $d r u$ & 'wood' & {$[d u]$} \\
\hline & & $g r>g$ & grua & 'woman' & [gua] \\
\hline & & $p r>p$ & prit & 'wait' & [pit] \\
\hline & & $t r>t$ & treni & 'train' & [teni] \\
\hline & & $k l>k$ & klima & 'climate' & [kima] \\
\hline & & $k r>k$ & kremi & 'cream' & [kemi] \\
\hline & & $p l>p$ & plepi & 'poplar' & [pepi] \\
\hline \multirow[t]{2}{*}{ b) } & $F+L \rightarrow F$ & $f l>f$ & flas & 'talk' & [fas] \\
\hline & & $v r>v$ & vras & 'kill' & [vas] \\
\hline \multirow[t]{5}{*}{ c) } & $F+S \rightarrow S$ & $s k>k$ & ski & 'ski' & [ki] \\
\hline & & $s t>t$ & stoli & 'stool' & [toli] \\
\hline & & $\int k>k$ & shkopi & 'stick' & [kopi] \\
\hline & & $\int t>t$ & shtata & 'seven' & [tata] \\
\hline & & $\int p>p$ & shpoj & 'pierce' & [poj] \\
\hline \multirow[t]{5}{*}{ d) } & $S+G \rightarrow S$ & $c j>c$ & cjapi & 'goat' & [tsapi] \\
\hline & & $d j>d$ & djeg & 'burn' & [deg] \\
\hline & & $k j>k$ & kjo & 'this' & [ko] \\
\hline & & $p j>p$ & pjata & 'dish' & [pata] \\
\hline & & $t j>t$ & tjetër & 'other' & [teta] \\
\hline
\end{tabular}

